
$\int \begin{aligned} & \text { Revista del instituto de ciencias } \\ & \text { Jurídicas de puebla, méxico, año } \mathrm{V}\end{aligned}$ NO. 28, JULIO-DICIEMBRE DE 2011,PP. 243-277

\title{
El derecho internacional de los derechos humanos y su apertura al principio del Gender Mainstreaming: el caso español*
}

\author{
International Law of Human Rights and \\ its Application to the Principle of Gender \\ Mainstreaming: The Spanish Case
}

\section{Juana María Gil Ruiz**}

\section{RESUMEN}

El derecho internacional tiene claro el urgente objetivo de eliminar las desigualdades entre mujeres y hombres, asi como promover su igualdad. No en vano, el principio de transversalidad de género parte del compromiso de la comunidad internacional para lograr la igualdad entre los géneros, así como el desarrollo y la paz para todas las mujeres. Este trabajo pretende abordar, en el marco de las nuevas técnicas legislativas que exigen dicha perspectiva, la implementación del principio de Gender Mainstreaming por parte de la administración española, analizando los obligados Informes de Evaluación de Impacto de Género (IEIG) que deben acompañar las disposiciones normativas que elabore el gobierno por Ley 30/2003, del 13 de octubre, como los planes de especial relevancia económica, social, cultural y artistica, por mandato de la L.0.3/2007, del 22 de marzo.

PALABRAS CLAVE: Mainstreaming de género, técnicas legislativas, Informes de Evaluación de Impacto de Género (IEIG), políticas públicas, desarrollo reglamentario.

\section{ABSTRACT}

This paper originates from the required and necessary incorporation of the gender perspective, as stated in international and European commitments. This paper aims to study within the framework of the new legislative techniques, the implementation of the so-called principle of gender mainstreaming by the Administration of the Spanish State. It analyses the required Gender Impact Assessment Reports which must accompany any regulatory measures set out by the Spanish Government according to Law 30/2003, set on October 13th, as well as plans of special economic, social, cultural and artistic importance, according to L.0. 3/2007, set on March 22nd.

KEY WORDS: Gender Mainstreaming, legislative techniques, gender impact assessment report, public policy, regulatory implementation.

* Recibido: 25 de junio de 2011. Aprobado: 16 de julio de 2011.

** Profesora titular de Filosofía del derecho, Universidad de Granada, España (jgil@ugr.es). 
JUANA MARÍA GIL RUIZ

\section{Sumario}

1. Igualdad y derecho internacional

2. Desarrollo reglamentario de la transversalidad: planteamiento del problema

3. Análisis de los IEIG elaborados por la administración según la legislación especifica

4. La regulación de la memoria del análisis de impacto normativo: el impacto por razón de género

5. Autoria -especializada- y contenido -especifico- de los IElG: necesaria formación en género

6. Tempus et modus

7. Breve referencia a los presupuestos y al enfoque de género

8. Conclusiones y propuestas

\section{Igualdad y derecho internacional}

Hablar hoy de lgualdad, con mayúsculas, exige conocer y manejar con rigor el concepto de transversalidad, o, mejor dicho, la correcta transposición del principio de Gender Mainstreaming a las legislaciones nacionales, por sus importantes repercusiones sociales, jurídicas y políticas en la ciudadanía. Sin duda, el principio de transversalidad de género parte del compromiso de la comunidad internacional para lograr la igualdad entre los géneros, así como el desarrollo y la paz para todas las mujeres. Sus precedentes internacionales inmediatos son de sobra conocidos: la Conferencia Mundial de las Mujeres en Nairobi en 1985, la propuesta de la Comisión sobre la Condición Jurídica y Social de las Mujeres de Naciones Unidas en 1987, o, a nivel europeo, el 11 Programa de Acción Comunitaria en materia de lgualdad de Oportunidades (1991-1995).

Pero sin duda, es la iv Conferencia Mundial sobre la Mujer celebrada en Beijing, en 1995, la que renueva el compromiso con la igualdad y proclama la transversalidad y el triunfo de lo que podríamos calificar "feminismo de Estado". En la Declaración de Beijing, los gobiernos participantes adoptaron y se comprometieron "a aplicar la siguiente Plataforma para la Acción, garantizando que en todas nuestras políticas y programas quede reflejada la perspectiva de género”, e invita a todos los gobiernos y a los demás agentes a "integrar la perspectiva de género (Gender Mainstreaming) -como corriente principal- en las legislaciones, en las políticas, programas y proyectos públicos", 1 con el objetivo de analizar sus posibles consecuencias para las mujeres y los hombres, respectivamente, antes de tomar decisiones vinculantes. Posteriormente, este compromiso ha sido reconfir-

1 La Declaración de Beijing y Plataforma para la Acción, elaboradas en la ı Conferencia Mundial sobre las Mujeres de Beijing (1995), se han publicado en la Serie Documentos del Instituto de la Mujer, 1996. 
mado en numerosas ocasiones, persiguiendo y analizando los mecanismos para incrementar la responsabilidad de los gobiernos en el cumplimiento del mandato que figura en la Plataforma de Acción.

Ya no hablamos, pues, de un principio de igualdad limitado, que parte de una visión sectorial del mismo, esto es, en relación con sí mismo, sino desde una visión más compleja y rica, desde una dimensión universal, que pone el principio en relación con el resto de las normas jurídicas. Para ser más exactos, a partir de ahora el derecho no se sustentará en una razón universal (neutras respecto al sexo-género), sino que responde a una manifestación de poder (patriarcal, según la lógica de la teoría crítica feminista del derecho). De este modo, no bastará con equiparar los derechos de mujeres y hombres, ni la solución a tanta desigualdad descansa en leyes de igualdad sectoriales, incapaces de desactivar el componente masculino del derecho. Se pretende integrar la dimensión de la igualdad en la elaboración y en la aplicación de la totalidad de las normas jurídicas y de las políticas públicas, es decir, apostar por el principio de transversalidad de la dimensión de género.

Europa no ha quedado al margen de este compromiso con la igualdad efectiva intergéneros, pasando a formar parte de una de las prioridades de su agenda política. No en vano, se trata de:

un principio firme y creciente, en el seno de la Unión Europea. En efecto, ha sido reconocido por el artículo 3 del Tratado de Ámsterdam, que ha incluido, como de una de las prioridades a tener en cuenta en el diseño de Políticas Europeas, la promoción de la lgualdad de mujeres y hombres en todas las políticas y la eliminación de las discriminaciones. Se incluye como objetivo de la Unión, la promoción de la igualdad entre hombres y mujeres (hasta el punto de condicionar) el conjunto de las Políticas Comunitarias al objetivo de la consecución de esa igualdad. ${ }^{2}$

De este modo, el fin de la igualdad no se alcanza a través de una o varias acciones específicas, sino integrándolo en todas las acciones.

El artículo 3.2 del Tratado de Ámsterdam explicita claramente el objetivo de la Unión Europea: "En todas las actividades contempladas en el presente artículo, la Comunidad se fijará el objetivo de eliminar las desigualdades entre el hombre y la mujer y promover su igualdad". El reciente Tratado de Lisboa se pronuncia en idénticos términos en su artículo 8: "En todas sus acciones, la Unión se fijará el objetivo de eliminar las desigualdades entre el hombre y la mujer y promover su igualdad".

\footnotetext{
${ }^{2}$ Véase Rey Martinez, F. "Comentario a los informes del Consejo de Estado sobre el impacto por razón de género", en Teoría y Realidad Constitucional, No. 14, 20. semestre de 2004, pp. 500-523.
} 
En este sentido,

[...] la Comisión de la Unión Europea ante la constatación de que decisiones políticas que, en principio, parecen no sexistas, pueden tener un diferente impacto en las mujeres y en los hombres, a pesar de que dicha consecuencia ni estuviera prevista ni se deseara, aprobó (en 1996) una Comunicación ${ }^{3}$ sobre la transversalidad Mainstreaming -introduciéndola en el Tratado de Ámsterdam (1997) - como un primer paso hacia la realización del compromiso de la Unión Europea de integrar la perspectiva de género en el conjunto de las políticas comunitarias y elaboró una Guía para la Evaluación del Impacto en Función del Género ${ }^{4}$ diseñada para proyectarse en el seno de la Comisión con objeto de evitar consecuencias negativas no intencionales que favorezcan situaciones de discriminación y para mejorar la calidad y la eficacia de las políticas comunitarias. ${ }^{5}$

De este modo, y como complemento a los objetivos de la acción comunitaria prevista para la promoción de la igualdad efectiva de mujeres y hombres, merece destacarse la aprobación de la Decisión del Consejo ${ }^{6}$ 2001/51/CEE, del 20 de diciembre de 2000, por la que se establece un programa de acción comunitaria ( $\mathrm{V}$ Programa Marco) sobre la estrategia (сом 2000, 335 final) que debe seguirse en materia de igualdad de mujeres y hombres (2001-2005), sustentándose en los principios derivados de la transversalidad y en la Hoja de ruta para la igualdad entre hombres y mujeres 2006-2010. Este Programa Marco, de enfoque dual,

[...] es uno de los instrumentos necesarios para la puesta en práctica de la estrategia global comunitaria en materia de igualdad entre mujeres y hombres, que abarca todas las políticas y todas las acciones comunitarias encaminadas a alcanzar dicha igualdad, incluidas las políticas de integración de la igualdad de los sexos y las acciones específicas dirigidas a las mujeres.

Y destaca por conceder un especial protagonismo a la evaluación del impacto de género en todos los ámbitos de intervención (vida económica, social, política, vida civil, roles y estereotipos [...]) que tengan repercusiones directas o indirectas en las mujeres o en los hombres, "como una de las acciones a emprender para

${ }^{3}$ Comunicación "Integrar la igualdad de oportunidades entre hombres y mujeres en el conjunto de las políticas y acciones comunitarias", com (96) 67 final del 21 de febrero de 1996.

${ }^{4}$ Guia para la Evaluación del Impacto en Función del Género, de la Comisión Europea, 1998.

${ }^{5}$ Exposición de Motivos de la Ley 30/2003, del 13 de octubre, sobre medidas para incorporar la valoración del impacto de género en las disposiciones normativas que elabore el gobierno.

${ }^{6}$ No obstante, el principio de transversalidad en el ámbito del ordenamiento jurídico comunitario se consolida en la Decisión del Consejo 95/593/cEe, del 22 de diciembre de 1995, relativa a un programa de acción comunitaria a medio plazo para la igualdad de oportunidades entre hombres y mujeres (1996-2000). 
el logro de los objetivos mencionados en el referido programa". Ello explica el sentido de la transversalidad y exige que "en el diseño y aplicación de todas las políticas hay(a) que tener en cuenta las preocupaciones, las necesidades y aspiraciones de las mujeres, en la misma medida que las de los hombres".

$Y$ esto es así porque de sobra es conocido que el modelo de políticas públicas existente en el mundo, y por supuesto en Europa, no ha sido pensado con la idea de garantizar la equidad de género. Por el contrario, las mujeres acceden en menor medida que los varones a la educación. De hecho, más de dos tercios de las personas analfabetas del planeta son mujeres. Asimismo, las personas son titulares de importantes derechos sociales en función de su posición en el mercado de trabajo, y ello implica -en tanto que la vinculación de las mujeres es menor y sus condiciones de precariedad son mayores que la de los compañeros varones- una penalización, o mejor dicho una discriminación en el acceso a los derechos sociales derivados del empleo, como las pensiones de jubilación.

El legislativo español, en esta línea de trabajo e impulsado por las demandas internacionales (Beijing, 1995) y europeas (Tratado de Ámsterdam y Tratado de Lisboa), ha apostado recientemente por un nuevo derecho antisubordiscriminación, ${ }^{9}$ que debe incorporar la perspectiva de género, de manera transversal y principal. Esta integración de la dimensión de la igualdad de oportunidades en la totalidad de los procesos normativos -elaboración, interpretación y aplicación- de la totalidad de las normas y en la totalidad de las políticas públicas -se manifiesten a través de normas o de actos administrativos no normativos- se denomina transversalidad, traducción del neologismo inglés Gender Mainstreaming.

Resultado de este esfuerzo legislativo son las (des)conocidas y polémicas Ley Integral (L.o. 1/2004, del 28 de diciembre), Ley de lgualdad (L.0. 3/2007, del 22 de marzo), sin olvidarnos de la Ley 30/2003, del 13 de octubre, sobre medidas para incorporar la valoración del impacto de género en las disposiciones

\footnotetext{
7 Decisión del Consejo 2001/51/CEE, del 20 de diciembre de 2000, relativa a un programa de acción comunitaria sobre la estrategia comunitaria en materia de igualdad entre hombre y mujeres (2001-2005). El texto de la Decisión del Consejo se transcribe literalmente en la Exposición de Motivos de la Ley 30/2003, del 13 de octubre, sobre medidas para incorporar la valoración de impacto de género en las disposiciones normativas que elabore el gobierno. BOE, No. 246, del 14 de octubre de 2003, pp. 36770 y 36771.

${ }^{8}$ Véase Comunicación de la Comisión al Consejo, al Parlamento Europeo, al Comité Económico y Social y al Comité de las Regiones, relativa a una Estrategia Marco Comunitaria sobre igualdad de hombres y mujeres (2001-2005).

${ }^{9}$ Tomo esta expresión de Ma. Ángeles BARRÉRE, con la que sin duda comparto sus posiciones en torno a la necesidad de apostar por un nuevo modelo de derecho antidiscriminatorio crítico, que supere las limitaciones de "la igualdad de trato y de oportunidades" como modelos válidos para construir éste, y se centre en erradicación de la subordinación estructural-grupal de las mujeres. Al respecto, pueden consultarse múltiples trabajos, a saber: BARRėRE, M. A. "Problemas de derecho antidiscriminatorio: subordinación versus discriminación y acción positiva versus igualdad de oportunidades", en Revista Vasca de Administración Pública, No. 60, 2001, pp. 145-166, o el más reciente, "La interseccionalidad como desafio al mainstreaming de género en las politicas públicas", en Revista Vasca de Administración Pública, No. 87-88, 2010, p. 251.
} 
normativas, encabezadas, sin duda, por los artículos 9.2 y 14 de la Constitución Española. Sin duda, el artículo 2.k) de la Ley $\operatorname{lntegral~}^{10} \mathrm{y}$, con mayor amplitud, el artículo 15 de la Ley de lgualdad han supuesto la consagración expresa del principio de transversalidad, con la asunción lógica de todas sus consecuencias: la universalidad de la igualdad y la integración de la dimensión de género.

En cuanto a la primera, la universalidad de la igualdad, hablamos no sólo de una universalidad subjetiva, que afecta a todos los poderes públicos, sino objetiva, dirigida a todas las ramas del ordenamiento jurídico. El arriba citado artículo 15 de la ley de lgualdad establece la vinculación transversal de la igualdad "en la actuación de todos los poderes públicos”, y esta universalidad subjetiva la ratificará su carácter de norma básica, tal y como se recoge en la Disposición adicional 1a. de la Ley.

La universalidad objetiva se contemplará, siguiendo la lectura del artículo 15 de la Ley de lgualdad, no sólo cuando alude a la "adopción y ejecución de sus disposiciones normativas", sino a "la definición y presupuestación de políticas públicas en todos los ámbitos y en el desarrollo del conjunto de todas sus actividades".

En cuanto a la segunda, la integración de la dimensión de género, en el proceso de elaboración de normas legislativas a propuesta del gobierno, se modifica el apartado 2 de artículo 22 de la Ley 50/1997, del 27 de noviembre, del gobierno, en el sentido de que "el procedimiento de elaboración de anteproyectos de Ley [...] se iniciará en el Ministerio o Ministerios competentes mediante la elaboración del correspondiente Anteproyecto, que irá acompañado por [...] un informe sobre el impacto por razón de género de las medidas que se establecen en el mismo". En este mismo sentido, y en cuanto a la integración de la dimensión de género en el proceso de elaboración de normas reglamentarias emanadas del gobierno, se añade un párrafo 1.b) del artículo 24 de la Ley 50/1997, del 27 de noviembre, del gobierno, afirmando que "en todo caso, los reglamentos deberán ir acompañados de un informe sobre el impacto por razón de género de las medidas que se establezcan en el mismo". Posteriormente, la Ley de lgualdad de 2007, en su artículo 19, ampliará tal exigencia a "los proyectos de disposiciones de carácter general y los planes de especial relevancia económica, social, cultural y artística que se sometan a la aprobación del Consejo de Ministros".

El atractivo de la transversalidad de género, sin duda, descansa en su potencial transformador a gran escala, esto es, en las múltiples posibilidades de este

10 Artículo 2.k) de la L.0.1/2004, del 28 de diciembre, de Medidas de Protección Integral contra la Violencia de Género, sobre principios rectores de la ley: "Garantizar el principio de transversalidad de las medidas, de manera que en su aplicación se tenga en cuenta las necesidades y demandas especificas de todas las mujeres victimas de violencia de género". 
principio como eje transformador simultáneo y unívoco en todas las áreas de la política. Y ello es así porque este proceso excede del mero proceso de elaboración de las normas, reatravesando su aplicación e interpretación y su planeamiento político, y su óptima implementación, neutraliza los estereotipos de género latentes en los mismos.

Sin embargo, tal y como deduciremos de este artículo, sus virtudes se convierten en debilidades, al haber levantado falsas expectativas de igualdad efectiva y de compromiso coordinado de los poderes públicos que aún hoy quedan muy lejos de ser una realidad. Conseguir los objetivos perseguidos por el Gender Mainstreaming requiere cambios catárticos, que no se consiguen de manera inmediata, y demanda, tal y como denuncian los organismos internacionales; revisión profunda de la gestión de las políticas, compromiso serio de los tres poderes del Estado con la igualdad efectiva y formación en género de todo el personal implicado en su puesta en marcha.

Asimismo, el nuevo derecho antidiscriminatorio y antisubordinación exige romper con una estructura de trabajo primitiva y desfasada -aunque dogmáticamente incorporada, incluso por las facultades de derecho- de funcionamiento del fenómeno jurídico, y de los criterios básicos de igualdad -tradicional desde Aristóteles en el pensamiento occidental-y de discriminación -centrada en un contexto individual, que no estructural y grupal-, que manipula.

Se trata de una ardua tarea que apenas se acaba de acometer desde el derecho y desde el pensamiento crítico del derecho, y que centrado en la transversalidad de género parte de dos axiomas:

1) El reconocimiento de la masculinidad del ordenamiento jurídico que obliga a su revisión crítica.

2) La insuficiencia de los mecanismos tradicionales de tutela antidiscriminatoria, basados en el sexo, a los fines de la igualdad de género, lo que obliga a una revisión global del derecho y a la apuesta de un nuevo derecho antisubordiscriminación.

En paralelo, preocupa que el haber acuñado la transversalidad, sin haber realizado la catarsis anteriormente citada, ponga en peligro los avances pro igualdad conseguidos con no poco esfuerzo, desmantelando toda la infraestructura institucional -impulsada por la Unión Europea- para apoyar las políticas de género. La apariencia de igualdad -al cumplir, como se constatará, el trámite vacuo del Informe de Evaluación de Impacto de Género (IEIG)-, implicaría la desaparición de los fondos, instituciones y programas específicos para la promoción de la igualdad de género. 
JUANA MARÍA GIL RUIZ

No entender esto, ni conocer la complejidad del Gender Mainstraming, además de no estar preparados para acometerla con rigor, implica -desde el desconocimiento-perpetuar o incrementar, en su caso, la discriminación contra las mujeres, esta vez desde la estructura jurídico-política formulada, en teoría, para erradicarla. Reparar, pues, en ella -en un contexto de necesaria formación en género de profesionales del derecho- es el objetivo de este artículo, y muy especialmente entendemos fundamental el análisis de uno de los instrumentos arbitrados para integrar de forma activa la transversalidad de género como corriente principal en la actuación de los poderes públicos. Nos referimos a los referidos Informes de Evaluación de Impacto de Género y a cómo éstos se vienen implementando en nuestro sistema jurídico-político.

El estudio que se presenta constatará que la aplicación del principio de transversalidad, a través de los preceptivos Informes de Evaluación de Impacto de Género (IEIG), inexistentes en algunos casos y descuidados en su ejecución en otros, no sólo no ha servido para eliminar la brecha estructural de desigualdad en la ciudadanía, sino que la ha engrosado, pero esta vez desde el procedimiento legislativo y ejecutivo en cuestión. Asimismo, su no persecución y fiscalización por parte del Poder Judicial ha permitido que su teórica efectividad sea más que decepcionante, y que se legitime, a través de un procedimiento vacuo de perspectiva de género, no motivado, la adopción de una medida legislativa, administrativa y/o política que perpetuará la subordinación estructural intergéneros, con apariencia o, mejor dicho, travestido de transversalidad.

\section{Desarrollo reglamentario de la transversalidad: planteamiento del problema}

Desde que en 2003 se exigiera la elaboración de los Informes de Evaluación de Impacto de Género (en lo sucesivo IEIG) en las disposiciones normativas que elaborara el gobierno, por Ley 30/2003, del 13 de octubre, pasando por la Ley Orgánica de lgualdad de $2007^{11}$ que amplía su obligatoriedad a los planes de especial relevancia económica, social, cultural y artística, hasta la actualidad, en que se ha aprobado su particular desarrollo reglamentario, lo cierto es que el balance al respecto de la calidad y cantidad de los IEı ha sido más que insuficiente.

No en vano, buena parte de los problemas que plantean éstos y de las críticas que se les ha vertido, descansan en el vacío reglamentario en tiempo y forma -establecido por la Ley 30/2003, y reiterado por la Ley de lgualdad de 2007-

\footnotetext{
11 Artículo 19 de la L.0.3/2007, del 22 de marzo, para la Igualdad Efectiva de Mujeres y Hombres.
} 
que ha generado confusión e inexistencia de pautas homogéneas que regulara la elaboración de los IEIG de las disposiciones normativas y políticas que elaborara el gobierno, tanto en el fondo como en la forma. Y es que:

(u)na vez que se aprueba esta ley y se hace exigible ese informe de impacto, en ningún lugar se puede llevar a cabo esa valoración, ni consta en la propia ley de qué organismo e instituciones se va a recabar el criterio o baremo para considerar que estamos ante una ley que transgrede la igualdad de género [...] La aprobación de una ley con la previsión de informe sobre impacto de género sin sujeción a criterio alguno, deja prácticamente fuera de toda posibilidad, que, hasta que no se produzca en efecto una nueva legislación sobre criterios y baremos, se pueda hablar de efectividad de la norma. ${ }^{2}$

El Real Decreto 1083/2009, del 3 de julio, ${ }^{13}$ se hizo esperar, así como la aprobación tardía, el 11 de diciembre de 2009, de la Guía metodológica para la elaboración de la Memoria de Análisis del Impacto Normativo, agotando prácticamente los plazos fijados por la Disposición Final Tercera del R.D. 1083/2009, que establecía: "Este Real Decreto, una vez publicado en 'Boletín Oficial del Estado', entrará en vigor el día siguiente al de la aprobación por el Consejo de Ministros de la Guía Metodológica a que se refiere la disposición adicional primera y, en todo caso, el 10. de enero de 2010".

Es verdad que la Exposición de Motivos de la Ley 30/2003, del 13 de octubre, alude a una "Guía para la evaluación del impacto en función del género" 14 elaborada por la Comisión de la Unión Europea, explicando que "(fue) diseñada para proyectarse en el seno de la Comisión con objeto de evitar consecuencias negativas no intencionales de discriminación y para mejorar la calidad y la eficacia de las políticas comunitarias". Pero pese a su proyección hacia ese funcionamiento interno, lo cierto es que su alusión en la Exposición de Motivos de la Ley hubiera justificado su uso como instrumento válido para la realización de los

\footnotetext{
12 Balaguer Callejón, M. L. "Ley 30/2003, sobre medidas para incorporar la valoración del impacto de género en las disposiciones que elabore el gobierno", Artículo 14, una perspectiva de género, Boletín de Información y Análisis Jurídico, 2003, No. 14, p. 25.

${ }_{13}$ Real Decreto 1083/2009, del 3 de julio, por el que se regula la memoria del análisis del impacto normativo. BOE, No. 173, del 18 de julio de 2009, p. 60174

${ }_{14}$ Guía para la Evaluación del Impacto en Función del Género (1998), Comisión Europea.

La Guía europea se estructura en cuatro apartados: el I, titulado "Introducción", el II, titulado "Los conceptos básicos", el II, titulado "Pertinencia con respecto al género", que incluye un subapartado sobre "Comprobación de la pertinencia con respecto al género", y el Iv, titulado "Evaluación del impacto en función del género", incluyendo un subapartado sobre "Criterios para la evaluación del impacto en función del género", concluyendo con "Algunos ejemplos" clarificadores. No obstante, se trata de una Guia bastante escueta, con apenas ocho páginas de contenido, incluyendo los ejemplos prácticos que recoge.
} 
IEIG en territorio nacional -como lo fue, en cierto grado, a nivel autonómico-, ${ }^{15}$ hasta su reglamentación específica. También podría haberse utilizado la "Guía de aplicación práctica, para la elaboración de lnformes de Impacto de Género de las disposiciones normativas que elabore el Gobierno, de acuerdo a la Ley 30/2003", editada por el Instituto de la Mujer en $2005,{ }^{16}$ más completa incluso que la anterior. Al fin y al cabo se trata de una cuestión de compromiso personal y político con la igualdad efectiva de la ciudadanía, y con las demandas internacionales ${ }^{17} \mathrm{y}$ europeas ${ }^{18}$ de aplicación del principio de Gender Mainstreaming, ratificadas por España. Sin embargo, ninguna de estas guías ha sido utilizada como instrumento de trabajo de modo constante ${ }^{19}$ por los distintos ministerios, de modo que el caos procedimental y la heterogeneidad entre los distintos IEIG, emitidos incluso por el mismo Ministerio, resulta preocupante, vaciándolos de contenido y, sobre todo, desnudándolos de sentido.

Las comunidades autónomas no han quedado al margen de este caos procedimental, como es el caso de Canarias. El Instituto Canario de la Mujer elaboró, en octubre de 2005, un proyecto de decreto para regular la emisión de los informes de impacto de género, cuyo trámite normativo no prosperó, junto con un método de trabajo para su elaboración. ${ }^{20}$ No obstante, desde la entrada en vigor de la Ley 30/2003, hasta 2009, el Instituto Canario de la Mujer (Ісм) ha emitido 40 IEIG en disposiciones normativas a petición de distintos centros directivos del gobierno de Canarias. Otros departamentos, por el contrario, han emitido IEIG

15 Ejemplo de su aplicación autonómica, en cierto grado, lo encontramos en los IEIg elaborados por la administración andaluza. La guía europea es aplicada por todas las Consejerias de la Junta de Andalucía, para la elaboración de los IEIG, asi como para la elaboración de los IOIEg (Informes de Observaciones del Informe de Impacto de Género).

16 Guia de aplicación práctica para la elaboración de Informes de Impacto de Género de las Disposiciones Normativas que elabore el Gobierno, de acuerdo a la Ley 30/2003, elaborada por Fundación Mujeres, Instituto de la Mujer, 2005.

17 En la Iv Conferencia Mundial sobre la Mujer celebrada en Beijing, en 1995, se renovó el compromiso de la comunidad internacional para lograr la igualdad entre los géneros, así como el desarrollo y la paz para todas las mujeres. Como precedentes inmediatos podriamos citar la Conferencia Mundial de las Mujeres en Nairobi en 1985, la propuesta de la Comisión sobre la Condición Jurídica y Social de la Mujer de Naciones Unidas en 1987, o a nivel europeo, el III Programa de Acción Comunitaria en materia de Igualdad de Oportunidades (1991-1995).

252 ${ }^{18}$ A nivel europeo, el principio de transversalidad se consolida en la Decisión del Consejo 95/593/CEE, del 22 de diciembre de 1995, relativa a un programa de acción comunitaria a medio plazo para la igualdad de oportunidades entre hombres y mujeres (1996-2000). Asimismo, el Tratado de Ámsterdam (que incorporó la Comunicación (96) 67 final del 21 de febrero de 1996), el Tratado de Lisboa, o la decisión del Consejo 2001/51/CEE, del 20 de diciembre de 2000, por la que se establece un programa de acción comunitaria (v Programa Marco) sobre la estrategia comunitaria en materia de igualdad entre hombres y mujeres, 2001-2005 (сом 2000, 335 final), refuerzan el compromiso comunitario con el Gender Mainstreaming.

${ }^{19}$ Esta Guía sí ha sido utilizada por el Ministerio de Trabajo y Asuntos Sociales cuyos informes poseen una cierta similitud estructural, y sólo excepcionalmente por otros Ministerios, en alguna ocasión.

${ }^{20}$ Véase el documento elaborado y editado por el Instituto Canario de la Mujer, Orientaciones para la aplicación de la perspectiva de Género en las Politicas Públicas y la evaluación del impacto de Género en las disposiciones normativas, Servicio de Planificación y Programas del ICM, 2005 (actualizado el 1o. de junio de 2009). 
sobre disposiciones propias, sin que en estos casos el Instituto Canario de la Mujer haya conocido o asesorado sobre los criterios y procedimiento aplicados. ${ }^{21}$ La conclusión es un aparato administrativo a la deriva, sin rumbo y desnudo de la transversalidad de género.

En definitiva, este largo periodo de "alegalidad" desde 2003, hasta prácticamente 2010, amén de su posterior, deficitario y difuso desarrollo reglamentario -como analizaremos en este artículo-, ha supuesto un caos procedimental y nada homogéneo, al no existir consenso en algunos parámetros básicos de elaboración de los obligados IEIG, y en los que repararemos a continuación; a saber: órgano competente para emitirlo, cualificación, contenido, desarrollo y ejecución.

\section{Análisis de los IEIG elaborados por la administración según la legislación específica}

Una correcta implementación de los informes de evaluación de impacto de género (IEIG) constituye una medida de esencial importancia preventiva, en términos de tutela antidiscriminatoria, pues garantiza que la norma, medida o decisión analizada (anteproyecto, proyecto, reglamento o planes de especial relevancia económica, social cultural y artística) que se pretenda aprobar, carece de impacto adverso para más de la mitad de la ciudadanía (que no un colectivo minoritario) del mismo sexo, carente de justificación razonable, suficiente, objetiva y proporcional. Este chequeo y validación previo constataría y garantizaría que la norma, decisión o medida no es indirectamente discriminatoria y por lo tanto impugnable.

Sin embargo, el análisis de los IEIG que han acompañado a los Proyectos normativos desde que entró en vigor la Ley 30/2003 -como seguidamente analizaremos- no ha obtenido, ni cuantitativa ni cualitativamente, una especial mención. Todo lo contrario. En términos generales podemos afirmar que apenas si se ha cubierto como un mero formulario, vacío de contenido y falto de las mínimas garantías de rigor procedimental; a saber: no autoría, carecen de firma, no están fechados, ignorancia en la metodología de género, entre otras carencias de significativa importancia que inhabilitan al IEIG como instrumento básico de las políticas públicas de igualdad de género, por mucho que lo asevere la ley Orgánica de lgualdad.

\footnotetext{
${ }^{21}$ Recientemente se ha aprobado el Decreto 30/2009, del 19 de marzo, del presidente del gobierno de Canarias, por el que se establecen las normas internas para la elaboración y tramitación de las iniciativas normativas del gobierno y aprueba las directrices sobre su forma y estructura. Este decreto contempla la obligación de evaluar el impacto de género por todas las disposiciones normativas del gobierno de Canarias.
} 
Al respecto, y junto a nuestros datos, hemos apoyado nuestra investigación además, en dos estudios recientes, ${ }^{22}$ que recogen -no con pocas dificultadesalgunos de los IEıg presentados en fase parlamentaria. De hecho, se destaca la no coincidencia de datos entre ambos, pese que la fuente de información -Servicio de Archivo del Congreso-, es idéntica en las dos investigaciones, pero en donde parece regir el principio de no publicidad. ${ }^{23}$ Mientras la investigación de THEMIS destaca que en el periodo del 15 de octubre de 2003 hasta el 10. de octubre de 2005 hubo un total de 47 IEIG acompañando a los 53 Proyectos de Ley presentados; B. Collantes y A. Sanchis destacan que el Servicio de Archivo sólo habla de 17 , pese a que la información global facilitada por este elevaba a un $68.31 \%$ el porcentaje de Proyectos de ley (142/97) que venían acompañados de su correspondiente IEIG. De cualquier modo, y para evitar perdernos en los datos, nos referiremos concretamente al muestreo de $21 \mathrm{IEIG}^{24}$ recogidos en ambos estudios y que se centran en la franja temporal comprendida entre el 15 de octubre de 2003 y el 19 de junio de 2007, así como en otros IElg posteriores, recogidos no con pocos esfuerzos, insisto. Asimismo, las consignas se repiten en los IEIG que acompañan los reglamentos, ${ }^{25}$ como veremos, ya fueran estatales como autonómicos.

Algunos datos resultan especialmente llamativos, con lo que se puede concluir que aunque se está dando cumplimiento a lo dispuesto en la ley 30/2003 a través de los IEIG, éstos, por su descuidada ejecución, no están siendo nada eficaces, sino que, muy al contrario, están sirviendo para consolidar o aumentar la

22 Nos referimos al estudio de ThemIS, titulado "Estudio del Impacto de Género en las Leyes", y presentado por Carmen Pujol Algas, en el XVIII Congreso Estatal de Mujeres Abogadas, en Almeria, del 11 al 13 de noviembre de 2005, y al premiado por la Diputación Provincial de Jaén, por su originalidad y calidad, cuyas autoras son Collantes SÁnchez, B. y SANCHis VIDAL, A. La evaluación del impacto de género en la normativa estatal y andaluza, Instituto de Estudios Giennenses, Diputación Provincial de Jaén, 2009.

${ }^{23}$ Las dificultades para poder acceder a los IEIG de proyectos de ley y de reglamentos han sido también señaladas por Celsa Picó, asi como su persecución personal para que le facilitaran información al respecto de algunos de ellos. Véase su interesante artículo, PIcó, C. "Una visión jurisprudencial sobre algunos aspectos de la Ley para la Igualdad", Cuadernos Digitales de Formación, 2008, pp. 11-42. Asimismo, pese a que el artículo 1 de la Ley 30/2003, del 13 de octubre, sobre medidas para incorporar la valoración del impacto de género en las disposiciones normativas que elabore el gobierno, establece que Ios IEIG acompañarán también a los anteproyectos de ley, sin embargo, en el Archivo del Congreso de los Diputados, los citados IEIG sólo acompañan a los proyectos de ley. Insistimos en que en el estudio de B. Collantes y A. SANCHis se denuncia que si se intenta localizar los IElG como documentación adjunta a los anteproyectos de ley, éstos no se encontrarán, ya que ni los propios anteproyectos son accesibles. Véase Colantes, B. y SAnchis, A. La evaluación del impacto de género en la normativa estatal y andaluza, Instituto de Estudios Gienneses, Diputación provincial de Jaén, 2009, p. 105.

${ }_{24}$ De los 21, 17 fueron aportados por el Servicio de Archivo del Congreso a Collantes y Sanchis, mientras que los otros cuatro se recogen de los facilitados a Themis. El análisis de todos ellos, aparece en Collantes, B. y Sanchis, A. op. cit., pp. 109 y ss.

${ }^{25}$ No se recoge ningún IElG que acompañe a un reglamento en el estudio de B. Collantes y A. SAnchis, pese a sus desmedidos esfuerzos por localizarlos. 
brecha de desigualdad existente entre mujeres y hombres. Reparemos en algunos extremos, aspectos que deberemos tener en cuenta para la persecución motivada de estos informes posteriormente, y muy especialmente por el Poder Judicial:

1) Ninguno de estos IEIG aparece firmado, salvo uno. Sólo el IEIG relativo al "Proyecto de Ley por la que se crea el Consejo General de Colegios Oficiales de Psicólogos", emitido por el Ministerio de Educación y Ciencia, aparece rubricado, y es un varón quien estampa su firma. Ello no quiere decir que la autoría sea masculina, ya que su firma puede corroborar el trabajo conjunto de una comisión de personas que, en cualquier caso, se desconoce. Sin embargo, la presencia de mujeres, pues, sigue sin constatarse, y la paridad de las comisiones ni siquiera se plantea. Lo que sí parece claro es que la misión del ieIg de revisar, entre otros aspectos, el sexismo del lenguaje, brilla por su ausencia, ya que ni el propio título del Proyecto de Ley ha sido corregido de manera inclusiva, insistiendo en el "Colegio Oficial de Psicólogos”.

2) Al unísono con la carencia de firma, muchos de ellos no poseen fecha de emisión. La fecha resulta ser garantía de que se ha elaborado con anterioridad, de modo inmediato y simultáneo a la presentación de la iniciativa parlamentaria. Algunos de ellos, incluso, llegan a elaborarse con posterioridad, y se adjuntan al expediente -desconociéndose su contenido- una vez reclamado por el órgano judicial. Éste es el caso del Real Decreto 291/2004 del 20 de febrero, por el que se regula el régimen de tasa láctea, ${ }^{26}$ dictado a propuesta del Ministerio de Agricultura, Pesca y Alimentación y publicado en al вов No. 45, del sábado 21 de febrero de 2004.

3) Los IEIG aportados en los proyectos de ley por los distintos ministerios no parecen haber seguido las complejas pautas marcadas por las guias señaladas al efecto; a saber: "Guía para la Evaluación del Impacto de Género en Función de Género", de la Comisión Europea, o bien la "Guía de aplicación práctica, para la elaboración de Informes de Impacto de Género en las disposiciones normativas que elabore el Gobierno, de acuerdo a la Ley 30/2003". No en vano, el 66\% de los IEIG analizados, según datos aportados por La evaluación del impacto de género en la normativa estatal $y$ andaluza, ${ }^{27}$ apenas tienen un folio de extensión, y sólo 5 del total aplican las directrices marcadas. Buen ejemplo del abandono y nulo

\footnotetext{
${ }^{26}$ El análisis de este Real Decreto, repasando a su vez la sentencia del ts que fallara su impugnación, la sts 5327/2006; Rec. 44/04, puede encontrarse en GıL Ruz, J. M. Las nuevas técnicas legislativas en España, Tirant Lo Blanch, 2011. ${ }^{27}$ Collantes Sánchez, B. y Sanchis Vidal, A. La evaluación del impacto de género en la normativa estatal y andaluza, Instituto de Estudios Gienneses, Diputación provincial de Jaén, 2009, p. 113.
} 
interés por la emisión del IEıg descansa en el aportado por el Ministerio de Economía y Hacienda al "Proyecto de Ley por el que se modifica el régimen fiscal de las reorganizaciones empresariales y del sistema portuario, y se aprueban medidas tributarias para la financiación sanitaria y para el sector del transporte en carretera". Como reza en el estudio antes señalado "se concentra en 15 líneas sin sentido, imposibles de clasificar dentro de estructura alguna". ${ }^{28}$ Paradójicamente y de la mano del mismo Ministerio, el IEIG aportado para el "Proyecto de Ley del Impuesto sobre la Renta de las Personas Físicas y de Modificación Parcial de las Leyes de los Impuestos sobre Sociedades, sobre la Renta de no Residentes y Sobre el Patrimonio", sorprende por su rigor. Todo ello viene a confirmar que la elaboración de estos IEIG tiene autorías diferentes y desconocidas, algunas -las más- sin formación en género, y otras -las menos- con formación.

4) La cuarta de nuestras observaciones descansa, pues, en la preocupante ausencia de designación expresa respecto del órgano responsable de la autoría del IEIG, y ello conlleva una dejación acerca del contenido motivado del mismo. Este abandono de autoría no garantiza la formación necesaria en género del órgano que, en cada momento, lo emita. Ello implica no sólo descoordinación entre ministerios e intraministerios, pues depende particularmente de la persona o personas que lo elaboren, sino una grave ignorancia de género plasmada incluso en el contenido del informe, confundiendo categorías tales como "pertinencia de género" y "valoración del impacto de género". El IEIG redactado para el Real Decreto Ley 6/2004, del 17 de septiembre, relativo a la adopción de medidas urgentes para reparar los daños causados por los incendios e inundaciones acaecidos en las Comunidades Autónomas de Aragón, Cataluña, Andalucía, La Rioja, Comunidad Foral de Navarra y Comunidad Valenciana reza:

[...] en el citado Proyecto de Real Decreto de Ley no se introduce discriminación alguna por razón de sexo, por lo que la mayor o menor incidencia en el número de personas de distintos sexos que puedan beneficiarse de las medidas extraordinarias contenidas en dicha norma legal vendrá determinada únicamente por los criterios objetivos que permiten obtener la condición de beneficiario del mismo. ${ }^{29}$

Más recientemente, en el Pacto de Condiciones Laborales de los Funcionarios,$^{30}$ aprobado por el Pleno del Ayuntamiento de Castro Urdiales del

\footnotetext{
28 Ibidem, p. 116.

29 Ibidem, p. 117.

30 Para una información más detallada sobre este Pacto de condiciones laborales de los funcionarios del ayuntamiento
} 
23 de febrero de 2008, por el que se aprueba el Catálogo y Valoración de puestos de trabajo de la citada Corporación Municipal, y ante el que se interpone recurso contencioso-administrativo No. 505/2008 por la Administración General del Estado, se confunde desigualdad con discriminación, e igualdad de oportunidades con igualdad efectiva. Al respecto, el abogado del Estado alega "La omisión de la provisión de puestos de trabajo y de incidencias por razón de género con vulneración del artículo 51.a), f) y g) de la Ley 3/2007, del 22 de marzo para la lgualdad" en el proceso de elaboración de la disposición. Pese a que el Tribunal menciona la exigencia de IEIG por el artículo 55 de la Ley de lgualdad, en las pruebas de acceso al empleo público desconocemos si existió éste, y el contenido del mismo, por obviarse en la argumentación de la sentencia. No obstante, mucho nos tememos que no existió tal IEIG, habida cuenta de la importante confusión también del Tribunal -al unísono con lo alegado por el ayuntamiento de Castro Urdiales- entre desigualdad/discriminación e igualdad de oportunidades e igualdad efectiva. Ello le lleva a confirmar "respecto al Catálogo y Valoración de puestos de trabajo aprobado, que se impugna, ha respetado y no conculca por defecto de previsión la Ley Orgánica de lgualdad (3/07), ni el art. 74 del EBEP" (Fu 4 in fine), ya que "se consigna en cada uno de los puestos del Catálogo, la provisión por concurso, y demás, sin dato previo, acerca del sexo de la persona que ocupará el mismo" (Fj 4).

5) En este sentido, y en esta misma línea, suele repetirse en los IElG analiza$\operatorname{dos}^{31}$ en el seno de la Administración General del Estado, la letanía de que "las medidas planteadas no producen impacto de género por no contener la norma medidas discriminatorias". Ello significa desconocer gravemente el concepto jurídico de discriminación indirecta sobre el que se asienta el derecho antidiscriminatorio. El IEIG no puede limitarse a la exigencia de neutralidad del lenguaje normativo para corregir tan sólo discriminaciones directas, sino que apoyado en los datos desagregados por sexo debe dar cuenta de la realidad social a la que se aplica. Algunos de los IEIG que cumplen con la citada letanía "carecen de Impacto por razón de Género", sin mayor apoyo previo de los Indicadores de Género, son sorprendentemente: el Proyecto de Ley de publicidad y comunicación institucional; el Proyecto

de Castro Urdiales ante el que se interpondria recurso contencioso-administrativo por la Administración General del Estado (Recurso 505/08), en el marco de la sentencia del tss de Cantabria 178/2009, del 27 de febrero, que fallara al respecto, remito a mi trabajo GıL Ruzz, J. M. Las nuevas técnicas legislativas en España, Tirant Lo Blanch, 2011. Consúltese la ficha de la sentencia recogida en el addenda.

${ }^{31}$ En el estudio de THemIs, 18 de los 46 proyectos de ley analizados que acompañaban IEIG en la vill Legislatura hacian referencia expresa a esta letanía. 
de Ley de Tropa y Marinería e incluso el Proyecto de Ley sobre Técnicas de Reproducción Humana Asistida, que a priori -y sin entrar a mayores-, poseen un impacto de género más que significativo. Urge, pues, observar si una determinada medida afectará de modo distinto a mujeres y a hombres, previendo si potenciará o, en su caso, disminuirá -si se aprobara- las desigualdades de partida, con el fin de evitar que la ley o el reglamento produzca efecto discriminatorio alguno.

6) Este último aspecto conecta con un dato global más que preocupante, la mayoría de los IEıG analizados no recogen las pautas que deben acompañar a una óptima "Valoración del Impacto de Género"; a saber: 1. Análisis de la situación de partida; 2. Previsión de resultados; 3 . Valoración del impacto; 4. Medidas y recomendaciones; 5. Seguimiento; 6. Evaluación; 7. Corrección. Ello significa, tal y como se recoge en el estudio La evaluación del impacto en la normativa estatal y andaluza, que "el 71\% de los IEIG que estamos analizando no recogen ni una sola de las pautas descritas", limitándose a señalar, en el mejor de los casos, "que carecen de Impacto por Razón de Género". ${ }^{2}$

7) En esta línea, la realidad de los IEIG en los reglamentos no parece gozar de mejor suerte. El IEIG del Real Decreto 2393/2004, de desarrollo de la L.o. 4/2000, de derechos y libertades de los extranjeros en España, se despacha afirmando que no contiene disposiciones específicas relacionadas con el género y, por lo tanto, no tendrá impacto en este sentido. Lo mismo sucede en el Real Decreto 2397/2004, del 30 de diciembre, de cambio de sede de la Comisión del Mercado de Telecomunicaciones de Madrid a Barcelona, ${ }^{33}$ que se limita a subrayar la ausencia de discriminación, sin entrar a valorar los efectos que para la plantilla (desagregada en mujeres y hombres) podría suponer el cambio de sede, teniendo en cuenta, entre otros aspectos, los problemas de conciliación de la vida familiar, personal y laboral de las personas trabajadoras y sus especiales consecuencias para las mujeres. Curiosamente, el traslado de sede de Madrid a Barcelona supuso un incremento de la contratación femenina, pese a no incorporar el Real Decreto sometido a cuestión un IEIG motivado. El no traslado de la plantilla de trabajadores

32 Collantes Sánchez, B. y Sanchis Vidal, A. La evaluación del impacto de género en la normativa estatal y andaluza, Instituto de Estudios Gienneses, Diputación provincial de Jaén, 2009, p. 118. En el "Estudio del Impacto de Género en las Leyes", de THEMIS, antes referido, en 21 de los 46 proyectos que acompañaban IEIG, sólo se aseveraba que "carecen de impacto de género".

33 Para un análisis de este Real Decreto enmarcado en el estudio de la sentencia del ts que fallará su impugnación -sts 7504/2006; Recurso 53/05- remito a mi trabajo GIL RuIz, J. M. Las nuevas técnicas legislativas en España, cit Al respecto, véase también el Recurso 51/2005. Se recoge también en el addenda final del libro. 
de Madrid a Barcelona, y la nueva contratación de nuevo personal, supuso un incremento de la presencia de mujeres al haber concurrido en mayor número a la cobertura de los nuevos puestos de trabajo ofertados.

8) Otros IEIG que valoran positivamente el Proyecto de Ley ${ }^{34}$ Orgánica que acompañan no parecen especial y rigurosamente motivados, utilizando una adecuada metodología de género, incluso moviéndose en un contexto casi obvio de igualdad. Es el caso del Proyecto de Ley Orgánica por la que se autoriza la ratificación por España del Tratado por el que se establece una Constitución para Europa, firmado en Roma el 29 de octubre de 2009. Paradójicamente, la única alusión al impacto de género que hace descansa en la siguiente aseveración: "En conclusión -sin haber aludido antes a ello-, como ya se ha adelantado, el impacto de ratificación del nuevo Tratado de la Unión es sin duda positivo desde la perspectiva de género". ${ }^{35}$

9) Idéntica tónica se detecta en IEIG que acompañan Reglamentos. De este modo, en el lnforme del Real Decreto 520/2006, del 28 de abril, regulador de las entidades que presten servicio de asesoramiento a las explotaciones agrarias y la concesión de ayudas a su creación, adaptación y utilización, se destaca la prioridad de las mujeres en el acceso al asesoramiento, así como destinataria del incremento en la ayuda. Sin embargo, el análisis de impacto de género, partiendo del análisis de los datos de partida, reatravesado por el objetivo último que se pretende alcanzar, brilla por su ausencia. Una buena prognosis requiere de una correcta diagnosis.

\section{La regulación de la memoria del análisis de impacto normativo: el impacto por razón de género}

El 3 de julio de 2009, el Consejo de Ministros aprobó el Real Decreto 1083/2009 por el que se regula la Memoria del Análisis del Impacto Normativo con el objetivo de mejorar la calidad de las normas y tiene por objeto precisar el contenido de las memorias, estudios e informes sobre la necesidad y oportunidad de las normas proyectadas, así como de la memoria económica y del informe sobre el impacto por razón de género requeridos por la legislación vigente, que deben acompañar a los anteproyectos de ley y proyectos de reglamentos. La finalidad

\footnotetext{
34 En el estudio de Themis, en 4 informes de los 46 que acompañaban a los proyectos de ley presentados en la viII Legislatura, se pone de manifiesto que la aplicación de la norma supondrá un impacto positivo desde la perspectiva de género.

${ }_{35}$ Collantes Sánchez, B. y Sanchis Vidal, A. La evaluación del impacto de género en la normativa estatal y andaluza, Instituto de Estudios Gienneses, Diputación provincial de Jaén, 2009, p. 119.
} 
última de esta memoria es garantizar que, a la hora de elaborar y aprobar un proyecto, se cuente con toda la información necesaria para estimar el impacto que la norma supondrá para sus destinatarios y agentes, $\mathrm{y}$

[...] para ello resulta imprescindible motivar la necesidad y la oportunidad de la norma proyectada, valorar las diferentes alternativas existentes para la consecución de los fines que se buscan y analizar detalladamente las consecuencias jurídicas y económicas, especialmente sobre la competencia, que se derivarán para los agentes afectados, así como su incidencia desde el punto de vista presupuestario, de impacto de género, y en el orden constitucional de distribución de competencias. ${ }^{36}$

De la redacción del Real Decreto se detecta una especial preocupación por la incidencia económica y de competencia de la disposición que pretende aprobarse, más que su interés por controlar el impacto de género de la misma. Dicha aseveración además se constata en la posterior especificación que realiza, resaltando que:

[...] se ha prestado una especial atención a la valoración del impacto económico de las propuestas, entendidas como un concepto más amplio que la estimación del coste presupuestario y haciendo hincapié en el impacto sobre la competencia, así como a la adecuación del proyecto al orden constitucional de distribución de competencias.

Todo ello pese a que posteriormente pretendiera suavizarlo el Ministerio de Política Territorial y Administración Pública en la presentación de la Guía Metodológica para la elaboración de la Memoria de Análisis de Impacto Normativo, matizando sutilmente el párrafo. Reza así:

[...] para ello resulta imprescindible estudiar los motivos y oportunidad de la norma, valorar las diferentes alternativas existentes para la consecución de los fines que se buscan y analizar detalladamente las consecuencias jurídicas y económicas que tendrán desde todos los puntos de vista, tanto sobre la competencia, como presupuestario, de impacto de género, y en lo que tiene que ver con la distribución de competencias. ${ }^{37}$

De cualquier modo, este decreto no se centra estrictamente en el desarrollo reglamentario de los informes de impacto de género. De hecho, no se trata de

${ }_{36}$ Real Decreto 1083/2009, del 3 de julio, por el que se regula la memoria del análisis de impacto normativo. BOE, No. 173, del 18 de julio de 2009, p. 60174.

${ }^{37}$ Guía Metodológica para la elaboración de la Memoria del Análisis de Impacto Normativo. http://www.mpt.es.l areas/funcion_publica/iniciativas/impacto_normativo.html. 
una guía específica de impacto de género, sino que, precisamente con el propósito de ordenar y simplificar los (distintos) informes y memorias, que deben acompañar a los anteproyectos y proyectos normativos del gobierno, en el Real Decreto 1083/2009 se establece que éstos se incluirán en un único documento que llevará por rúbrica "Memoria del análisis de impacto normativo" -herramienta metodológica flexible (que no normativa) de carácter informador-, y que en ningún caso sustituye a la decisión política. Se limita a aportar información relevante para que los órganos competentes tomen las decisiones que estimen oportunas. ${ }^{38}$ Se trata, pues, de una herramienta para la mejora de la regulación, mediante la cual se sistematiza y ordena la información relevante para valorar el impacto de una iniciativa normativa con el fin de ayudar en el proceso de su aprobación.

Éste que sigue sería el esquema al que respondería la memoria del análisis del impacto normativo y su influencia final en la elaboración de la disposición final.

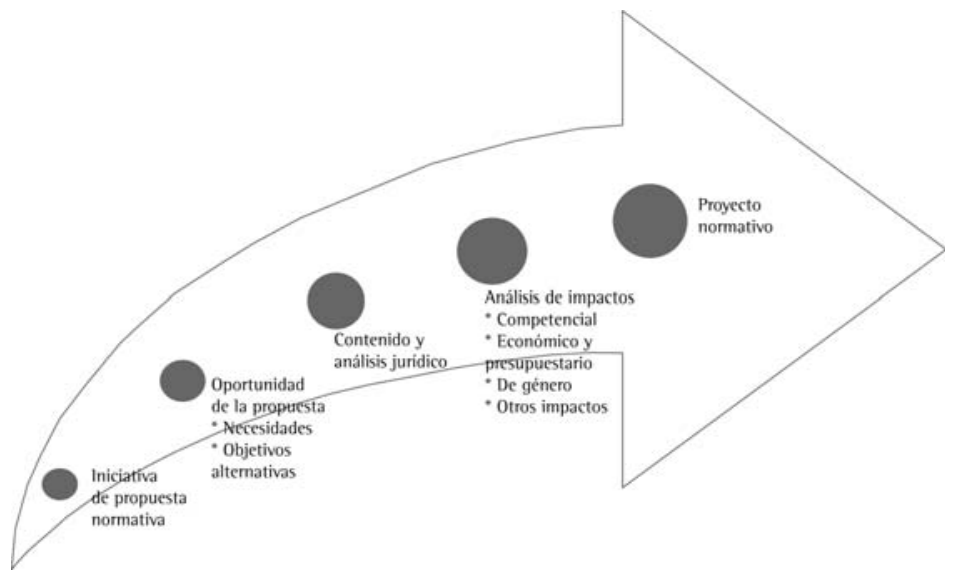

Por lo que respecta a los informes de impacto por razón de género -apunta- son una herramienta eficaz para introducir el principio de igualdad en las políticas públicas a través de los planes y las normas legales, facilitando una toma de decisiones basada en una mejor información: los posibles efectos que va a producir la medida sobre hombres y mujeres, advirtiendo a quienes la proponen sobre las consecuencias deseadas y las no deseadas y proponiendo, en su caso, su modificación. ${ }^{39}$

Este último apunte sobre su talante informador y no vinculante nos hace plantearnos si realmente el desarrollo reglamentario de los obligatorios IElG responde

\footnotetext{
${ }^{38}$ Cfr. ibidem, pp. 4 y 5

${ }^{39}$ Idem.
} 
a la garantía adicional que demandaba el artículo 3.2.a) de la Directiva 2002/73/ CE, del 23 de septiembre de 2002 -transpuesta en la Ley Orgánica de lgualdad de 2007 que exigía, a su vez, su desarrollo reglamentario-, a saber: los Estados miembros están obligados a adoptar "las medidas necesarias para garantizar que [...] se derogue cualquier disposición legal, reglamentaria o administrativa contraria al principio de igualdad de trato", garantía que sugerimos debería venir de la mano de los organismos de igualdad. Entendemos que esta exigencia va más allá que una mera propuesta o sugerencia de que se modifique la disposición, sino que se exige su derogación inmediata, lo que debería convertir a los IEIG motivados en una exigencia procedimental ineludible para la legalidad vigente.

Toda esta reflexión obliga a reparar en tres aspectos fundamentales: quién y qué condiciones debe ostentar el órgano emisor de los IEIG -aspectos vinculados a los objetivos que debe plasmar-, cuándo debe presentarlo y cómo debe hacerlo.

\section{Autoría -especializada- y contenido -específico- de los IElG: necesaria formación en género}

Con respecto a su autoría, al quién,

[...] la Memoria se elabora por el órgano o centro directivo impulsor y responsable de la propuesta normativa. Cuando se trate de una propuesta conjunta, la elaboración y actualización de la Memoria será responsabilidad del órgano o centro directivo de quien parte la iniciativa, si bien en ella participarán todas las unidades proponentes.

En ningún momento se hace referencia a la necesaria formación en género que debe tener el equipo decisor, ni al carácter paritario que debiera ostentar. Tampoco se repara en la autoría específica del mismo. Plantea la posibilidad de realizar consultas, pero en ningún caso permite la elaboración de la Memoria por otros órganos distintos. Probablemente este último matiz pretende cumplir con el sentido de la transversalidad Mainstreaming de género que debe estar presente en la elaboración, ejecución y aplicación de las normas, en la definición y presupuestación de políticas públicas en todos los ámbitos y en el desarrollo del conjunto de todas sus actividades, y que debe, pues, reatravesar la actuación de todos los poderes públicos. ${ }^{40}$ Sin embargo, este prometedor objetivo no puede desconocer la realidad, más que presente en España, y señalada por la

${ }_{40}$ Véase artículo 15 de la L.0. 3/2007, del 22 de marzo, para la Igualdad Efectiva de Mujeres y Hombres. 
Unión Europea ${ }^{41}$ de: insuficiente sensibilidad y concienciación ante la cuestión de género en los niveles de toma de decisiones, carencia de recursos humanos y presupuestarios, y la falta de experticia y de competencias en temas de género. El informe de la Comisión (сом [1998] 122 final) preconiza, entre otros compromisos pendientes: una mayor sensibilidad hacia la dimensión del género, principalmente de los ejecutivos; el desarrollo de las competencias en materia de igualdad de oportunidades; una evaluación regular del impacto de las políticas sobre la igualdad entre hombres y mujeres, y la comprobación sistemática de que se ha tenido en cuenta la igualdad entre mujeres y hombres en toda propuesta legislativa o cualquier otro documento político. Para lograr nuevos avances, la integración de la dimensión de género exige un planteamiento global más exhaustivo.

$\mathrm{Al}$ respecto puede jugar un papel muy importante las esperadas Unidades de lgualdad referidas en el artículo 77 de la t.o. 3/2007, del 22 de marzo, para la lgualdad Efectiva de Mujeres y Hombres que entre sus funciones se encuentra la de:

c) Asesorar a los órganos competentes del Departamento en la elaboración del informe sobre impacto por razón de género, d) Fomentar el conocimiento por el personal del Departamento del alcance y significado del principio de igualdad mediante la formulación de propuestas de acciones formativas, (así como) e) Velar por el cumplimiento de esta ley y por la aplicación efectiva del principio de igualdad.

También, incluso, podría plantearse la posibilidad de que el Instituto de la Mujer participara como interlocutor válido -aunque no de manera exclusiva-, entre otros, en el proceso de elaboración de los IEIG -como sí sucede en algunas Comunidades Autónomas- como garantía de su efectiva motivación. Sin embargo, en los distintos debates que tuvieron lugar durante el procedimiento legislativo ordinario de la Ley 30/2003, la propuesta de que fuera el Instituto de la Mujer el organismo encargado de la elaboración de los IEIG fue rechazada sistemáticamente. Éste no fue el caso, por ejemplo, de Cataluña, su referente normativo anterior -como explicamos- quien, sin embargo, en el Acuerdo del Consejo Consultivo de la Generalitat, del 15 de mayo de 2001, encarga al Instituto Català de la Dona (actualmente Institut Català de les Dones) la elaboración de los informes de impacto de género de las propuestas de disposición que se promueven ${ }^{42}$ (decretos,

\footnotetext{
${ }^{41}$ Véase el Informe de la Comisión sobre el seguimiento de la Comunicación (98 122 final). "Integrar la igualdad de oportunidades entre hombres y mujeres en el conjunto de las políticas y acciones comunitarias" [com (1998) 122 final].

${ }^{42}$ Al respecto, véase Gensana Riera, A. Informes d'impacte de gènere, Col-lecciò Eines, Ed. Insitut Català de les
} 
órdenes y anteproyectos de ley), a que se refiere el apartado 2 del artículo 63 de la Ley 13/1989, en un plazo de 10 días hábiles a partir de la recepción por éste del Proyecto de disposición que se promueve.

No participamos a priori de la idea de que sea el Instituto de la Mujer el que se responsabilice de manera exclusiva de la elaboración, redacción y emisión del informe -liberando de esta responsabilidad social, jurídica y política, a los responsables de cada política sectorial- pero sí de que participe de manera activa en el mismo, con una representación válida en la Comisión encargada (y dependiente del órgano o centro directivo impulsor) de presentar éste, de manera motivada. Cierto es, no obstante, que la previsión que algunas Comunidades Autónomas han hecho -como Cataluña-, encargando esta tarea al Instituto de la Mujer, al menos garantiza, en teoría, un cierto nivel de competencia en género, aun cuando no responda al espíritu del Gender Mainstreaming que debe reatravesar toda acción política en las administraciones públicas, ya explicado. De cualquier modo, el Instituto deberá impartir cursos formativos y desarrollar actividades que acerquen la perspectiva de género a las personas que participen de la elaboración del mismo.

Por el contrario, en segundo término, debe ser el Instituto de la Mujer quien de manera exclusiva y autónoma tenga la potestad de validar definitivamente el IEIG a través de un segundo informe que debiera ser obligatorio, preceptivo y vinculante. Nos referimos al Informe de Observaciones del Informe de Evaluación del Impacto de Género (IOIEG).

Y es que la metodología que incorpora la perspectiva de género no se intuye. ${ }^{43}$ De nada sirve un esfuerzo legislativo para incorporar los IEIG -aun cuando sea mejorable-si los operadores últimos, las personas que han de actuar, carecen del conocimiento y del compromiso que implica el nuevo derecho antidiscriminatorio. Tampoco la perspectiva de género, una perspectiva metodológica compleja que incorpora categorias técnicas que han de estudiarse, va vinculada a la mera sensibilidad; ni es tan sencillo como agregar o sumar la palabra "mujeres" a los discursos o análisis de la realidad, supuestamente, "con perfil de género". Tampoco se adquiere, insisto, con la realización de un curso sobre igualdad de oportunidades y prevención de violencia de género, obligado por la administración, de un máster o un experto en lgualdad de Oportunidades y Género, ni tan siquiera porque aparezca tratado en un tema del Temario de Oposiciones. No es

Dones", No. 3, 2005. También puede consultarse en la página web del Instituto: www.gencat.net/icdona/docs/impac todegenero.pdf.

${ }^{43}$ En este sentido, véase GIL RuIz, J. M. "Fundamento, urgencia y autoria de los esfuerzos legislativos para la erradicación de las violencias de género", en BENGOECHEA GIL, M. A. (ed.). La lucha por la igualdad efectiva de mujeres y hombres. Reflexiones y aportaciones de la Ley de Igualdad 3/2007, del 22 de marzo (presentación de Miguel LoRENTE), Dykinson, Madrid, 2020, pp. 45-82. 
una cuestión de cantidad -que también- sino de calidad. Incorporar esta categoría técnica reivindicativa obliga a tener que cortar las entrañas "machistas" y, en algunos casos, sexistas, generadas por la socialización diferencial patriarcal y ponerse las gafas de género para analizar la realidad, diagnosticarla y buscar alternativas inclusivas de todos lo seres humanos.

Sin duda, hoy el principal desafío de la Ley $^{44}$ es su aplicabilidad por parte de las personas intervinientes en el proceso de integración de la perspectiva de género en las legislaciones, en las políticas, programas y proyectos públicos, y de cómo éstas la hagan propia. Porque se trata de una cuestión de compromiso personal y voluntad política con la igualdad efectiva de la ciudadanía, y no un capricho o moda (fashion) que ahora se encuentra en la agenda europea y, en consecuencia, también en la nacional, autonómica o local.

En cierto modo, el legislador es consciente de dichas carencias formativas de género, en buena medida porque la perspectiva de género no ha sido enseñada ni aplicada en ninguna de las etapas educativas, ${ }^{45}$ ni tampoco en el ámbito de la enseñanza superior o de posgrado, lo que implica una enorme laguna que debe ser subsanada de manera urgente si se pretende cumplir de modo efectivo con todas las propuestas para la consecución de la igualdad efectiva que incluyen, sin duda, los necesarios informes motivados de impacto de género. No hacerlo así, no tomarse en serio la formación, no apostar por ella, significaría, en lo que a la elaboración de los IElG se refiere, un mero trámite vacuo, un sinsentido que sólo merecería ser eliminado.

Y ello es así en atención al contenido específico que debería contener el IElG, que no es menor, según la Guía Metodológica para la elaboración del análisis de impacto normativo, del 11 de diciembre de 2009, y que se basa en la refundición de las dos guías-madre ${ }^{46}$ citadas a lo largo de este artículo, a saber:

1) Identificación de los objetivos que en materia de igualdad entre mujeres y hombres se deben conseguir de forma activa a través de la norma que se pretende implantar.

\footnotetext{
${ }^{44}$ Al respecto, remito a mi trabajo GIL RuIz, J. M. Los diferentes rostros de la violencia de género. Ensayo jurídico a la luz de la Ley Integral y la Ley de Igualdad, Dykinson, Madrid, 2007.

${ }^{45}$ Actualmente la obligatoriedad de formarse en género, se recoge no sólo en la L.0. 3/2007, del 22 de marzo para la Igualdad Efectiva de Mujeres y Hombres, sino también en la L.0. 1/2004, del 28 de diciembre, de Medidas de Protección Integral contra la Violencia de Género. Sirvan como ejemplos salteados los artículos 23-25, 61 de la Ley de lgualdad, y los artículos 4, 6, 7, 15,20, 47 de la Ley Integral, entre otros.

${ }^{46}$ Nos referimos a la Guía para la Evaluación del Impacto en Función del Género, de la Comisión Europea, escueta pero esclarecedora con respecto a "La pertinencia de género", y a la Guia de Aplicación Práctica para la Elaboración de Informes de Impacto de Género de las Disposiciones Normativas que elabore el Gobierno, de acuerdo a la Ley 30/2003, de 2005, más completa que la anterior, pero deficitaria con respecto al item ya referido sobre "pertinencia de género", al omitirlo.
} 
JUANA MARÍA GIL RUIZ

2) Descripción de la situación de partida sobre la que va a actuar la norma, lo que se consigue atendiendo a dos tipos de indicadores:

a) Indicadores cuantitativos derivados de los datos estadísticos desagregados por sexo que se posean.

b) Indicadores cualitativos derivados del sistema de valores, creencias, costumbres $u$ opiniones sociales que, con el objetivo de identificar roles y estereotipos de género, puedan tener incidencia en el ámbito de la aplicación de la norma.

3) Previsión de resultados: se analiza y prevé el modo en que puede afectar la norma a la corrección de las desigualdades que caracterizan el punto de partida o a la mejora futura de las condiciones de igualdad entre mujeres y hombres.

4) Valoración del impacto de género de la norma que pretende aprobar y aplicar, calificando los resultados previstos en relación con la eliminación de las desigualdades entre mujeres y hombres, y el cumplimiento de los objetivos de políticas de igualdad. De este modo, se considerará que el impacto es negativo si no se prevé que la norma vaya a paliar la desigualdad de origen; positivo, en caso contrario, y nulo cuando en la situación de partida no concurran manifestaciones de desigualdad entre hombres y mujeres. Asimismo, se incorporarán a la Memoria todas aquellas recomendaciones sobre la aplicación de la norma y para el desarrollo de medidas complementarias que pudieran garantizar y fortalecer el impacto positivo de género.

Especificado el contenido que debe recogerse en los IEIG obligatorios, difícilmente podrán cubrirse todos estos ítems con garantía, si no se tiene formación específica en género. $Y$ es que de la misma manera que para diagnosticar, valorar y practicar una intervención quirúrgica de corazón de manera óptima se requiere y se garantiza institucionalmente la formación reglada en cirugía cardiovascular - conviniendo que ésta no se intuye y que nada tiene que ver con la sensibilidad del equipo médico que lo practique-, lo mismo debe suceder con la calidad de los informes por razón de género motivados que se exigen para diagnosticar, valorar y practicar la oportunidad y conveniencia de la medida normativa que se pretende aprobar. La formación en género, pues, se plantea fundamental, necesaria y obligatoria para el cumplimiento de la exigencia internacional, europea y nacional de emisión de los Informes de Valoración de Impacto de Género. 
Asimismo, ésta debería ser revisada por los organismos de igualdad al efecto, referidos anteriormente -Instituto de la Mujer [...]-, encargados, por ley, de la coordinación de políticas de igualdad y de formular recomendaciones sobre cualquier cuestión relacionada con la discriminación. La intervención de éstos, garantizaría el efectivo cumplimiento del IElG como trámite vinculante en el proceso de elaboración normativa, a través de lo que podría denominarse -extrapolando algunos aspectos ${ }^{47}$ del sistema andaluz- el lnforme de Observaciones del Informe de Evaluación del Impacto de Género (101EG), además de su recomendable presencia, como interlocutor válido, en la Comisión encargada de elaborar los IEIG en el Centro directivo impulsor de la propuesta normativa.

Haciendo mías las palabras de Alda FAcIo,

[...] en este paso lo que más me interesa enfatizar es que es indispensable que las personas que han tomado conciencia de la subordinación de las mujeres y que han profundizado en el análisis de los textos legales para identificar los sesgos androcéntricos, dicotómicos, etc., sean las mismas que redacten las propuestas y modificaciones a estos textos [...]..$^{48}$

Sin embargo, la formación en género debería asegurarse e incorporarse progresivamente en todos los actores políticos y sociales afectados, de modo que la tarea de incorporar la transversalidad no se derivara de manera automática a los Institutos de la Mujer, como si fuera "cosa de mujeres", aislado del compromiso de los poderes públicos en su totalidad. Se exige, pues, una mayor coordinación y un trabajo conjunto por parte de los responsables de cualquier política sectorial incorporando el Gender Mainstreaming y una mayor sensibilización, concienciación y formación en género de todos los implicados, que por supuesto incluye, los altos directivos -que no sólo el equipo técnico- de la administración y del gobierno, ya sea nacional, autonómico o local. ${ }^{49}$ No en vano la actual responsabilidad para impulsar y fomentar la realización del análisis de impacto

\footnotetext{
47 Pese a recomendar el Informe de Observaciones del Informe de Evaluación del Impacto de Género (IOIEG) como garantía de legalidad de la disposición normativa o reglamentaria que se esté elaborando, no participamos del sistema de verificación arbitrado por la Junta de Andalucía. Nos referimos al envío de la documentación recibida por el IAM que incluye el IEIG junto al anteproyecto de la disposición de que se trate a la Consultora LKaDI, S.L, empresa que presta servicios especializados en la gestación, ejecución y evaluación de proyectos ligados a acciones que favorezcan la igualdad de oportunidades de mujeres y hombres. No hay por qué externalizar servicios, con el coste que eso implica, teniendo (y debiendo tener) el Instituto Andaluz de la Mujer (IAM) recursos humanos y técnicos suficientes para poder valorar la idoneidad del IEIG de la disposición que se pretenda aprobar.

${ }^{48}$ Véase $\mathrm{FAClO}_{1} \mathrm{~A}$. Cuando el género suena, cambios trae (Una metodología para el análisis de género del fenómeno legal), ILANUd, San José de Costa Rica, 1999, p. 125.

${ }^{49}$ Aun cuando queda mucho por hacer en el ámbito local, merecen destacarse algunos esfuerzos puntuales de incorporación del enfoque de género en los presupuestos, como es el caso del ayuntamiento de Bilbao.
} 
normativo de los nuevos proyectos -y en consecuencia su impacto por razón de género- es competencia ahora de la Dirección General de Organización Administrativa y Procedimientos, de la Secretaría de Estado para la Función Pública del Ministerio de la Presidencia, y ya no de la Agencia Estatal de Evaluación de las Políticas Públicas y Calidad de los Servicios, ${ }^{50} \sin$ perjuicio de que se pueda recabar su colaboración puntual.

Sin embargo, ninguno de estos aspectos aparece recogido ni en el Real Decreto 1083/2009, del 3 de julio, por el que se regula la memoria del análisis de impacto normativo, ni en la Guía Metodológica para la elaboración de la memoria del análisis de impacto normativo, del 11 de diciembre de 2009, que despacha en apenas cuatro folios la referencia al impacto por razón de género, y donde, curiosamente, recoge una importante excepción: la elaboración del anteproyecto de Ley de Presupuestos Generales del Estado. Al respecto, la disposición adicional segunda del Real Decreto 1083/2009, del 3 de julio, referida al Anteproyecto de Ley de Presupuestos Generales del Estado, reza así:

La documentación que deberá acompañar al anteproyecto de Ley de Presupuestos Generales del Estado, será la establecida en el artículo 37.2 de la ley 47/2003, de 26 de diciembre, General Presupuestaria.

Anualmente, en la Orden del Ministerio de Economía y Hacienda por la que se dictan normas para la elaboración de los Presupuestos Generales del Estado, se incluirán las oportunas instrucciones para la evaluación del impacto de género.

No obstante, su peculiar tratamiento, exceptuado expresamente y distinto al resto de los Informes de Evaluación de Impacto de Género, justifica su abordaje en epígrafe aparte dedicado a los presupuestos con enfoque de género.

\section{Tempus et modus}

Con respecto al cuándo debe hacerse la memoria, ésta debe realizarse de manera simultánea a la elaboración del proyecto normativo, desde su inicio hasta su finalización. El Real Decreto 1083/2009, del 3 de julio, especifica que "se trata, por tanto, de un análisis previo a la aprobación de la norma, al objeto de garantizar que todas las políticas públicas contribuyan al objetivo de la igualdad y

\footnotetext{
${ }^{50}$ Disposición final primera del Real Decreto 1083/2009, del 3 de julio, por el que se regula la memoria del análisis del impacto normativo, que modifica el artículo 6.2, apartados 2) y j) del Estatuto de la Agencia Estatal de Evaluación de las Políticas Públicas y Calidad de los Servicios aprobado por el Real Decreto 1418/206, del 10. de diciembre, excluyendo de las atribuciones de la citada agencia las competencias correspondientes al análisis de impacto normativo.
} 
a una mejor cohesión social desde la perspectiva de género". Por lo tanto, éste deberá ser inmediato y simultáneo a la presentación de la iniciativa parlamentaria, y en ningún caso posterior a ella, para cumplir el trámite. Qué duda cabe, que la aportación del IEIG al expediente, debidamente fechado, es garantía del momento procedimental en que se elabora. Sin embargo, y pese a que el artículo 10. de la Ley 30/2003, del 13 de octubre, sobre medidas para incorporar la valoración del impacto de género en las disposiciones normativas que elabore el gobierno, establece que los IEIG acompañarán también a los Anteproyectos de Ley, sin embargo, en el Archivo del Congreso de los Diputados, los citados IElG sólo acompañan a los proyectos de ley. ${ }^{51}$

La última de las reflexiones, que gira en torno al modo en que debe presentarse la Memoria, la Guía hace alusión nuevamente de manera global a la presentación del Informe de Impacto Normativo que incluye la referencia específica al IElG. En este sentido, las memorias constarán, sin alteración de orden, de: resumen ejecutivo, que se caracterizará por su brevedad; seguido del cuerpo central de la memoria, que deberá ser, igualmente, conciso, y finalmente los anexos. Tanta insistencia en la brevedad y concisión nos preocupa pese a que se aluda, de manera genérica, a que "No será suficiente señalar 'de la propuesta normativa no se derivan impactos apreciables en los ámbitos [...]' sino que habría que justificar por qué no se aprecian los impactos en cada ámbito". ${ }^{52} \mathrm{Si}$ bien, en las memorias abreviadas, "en todo caso se especificarán los aspectos por razón de género del proyecto normativo, de acuerdo con lo establecido en el apartado IV.4 de esta Guía”, no parece que sea garantía de que el IEIG aparezca realmente motivado, en un marco de experticia en metodología de género, como hemos puesto de manifiesto al analizar los informes elaborados según la ley 30/2003, del 13 de septiembre.

\section{Breve referencia a los presupuestos y al enfoque de género}

Persiguiendo el compromiso de adopción del Gender Mainstreaming -o perspectiva de género como corriente principal- en el planeamiento y ejecución de toda medida normativa y/o política, qué duda cabe que a nivel macro urge un seguimiento del nivel de inserción de la perspectiva de la equidad de género en la política económica en sus diversas dimensiones. Habría que hacer especial hinca-

\footnotetext{
${ }^{51}$ El estudio de Collantes, B. y Sanchis, A. La evaluación del impacto de género en la normativa estatal y andaluza, cit., p. 105, denuncia no sólo la imposibilidad de localizar los IEIG adjuntos a los anteproyectos de ley, sino los propios anteproyectos.

${ }^{52}$ Guía Metodológica para la elaboración de la Memoria del Análisis de Impacto Normativo, 2009, p. 35.
} 
pié en la actualidad en el análisis de los planes de recuperación económica, en los Acuerdos de Asociación Económica y otros planes que tiene un impacto directo en la utilización de recursos públicos. Especialmente relevante sería insistir en el seguimiento crítico de las medidas que están tomando los gobiernos desde que estalló esta crisis a finales de 2007, desde los primeros planes de rescates masivos a entidades financieras, hasta las últimas propuestas y acuerdos de reformas de pensiones, pasando por las medidas clásicas de reactivación de corte keynesiano. ${ }^{53}$ Sin embargo, este análisis aquí apuntado no podrá ser abordado en nuestro ensayo jurídico-político -en tanto que se excede de nuestro objeto de estudio-, lo que no quita que urja investigarlo. Nos centraremos en este epígrafe en los presupuestos en clave de género.

El presupuesto con enfoque de género es una herramienta de análisis sobre el efecto de las políticas de gastos e ingresos en la consecución de la igualdad real y efectiva de la ciudadanía. A través del enfoque de género en los presupuestos públicos se puede favorecer la igualdad y corregir la discriminación no sólo a través de las partidas diseñadas específicamente para ello, sino también a través de partidas de carácter general, no específicamente asociadas a dichos objetivos. Éste es el sentido de la aplicación del Gender Maisntreaming, de la transversalidad de género como corriente principal, en la política presupuestaria. Sobre la importancia del mismo se manifiesta E. MARí cuando afirma: "No hay voluntad política que se sostenga sin recursos, sin presupuesto. Hablar de género en los presupuestos es hablar de igualdad de mujeres y hombres, evidenciar la desigualdad que permanece y comprometer recursos públicos". ${ }^{54}$

No se trata, pues, de un mero documento jurídico y financiero que recoge una expresión cifrada de ingresos y gastos relacionados con políticas generales dirigidas a la ciudadanía en su conjunto. $Y$ esto es así porque los presupuestos no son neutrales, sino que están reatravesados, en primer lugar, por el grado de compromiso político relativo a la equidad de género, compromiso que se traduce en destinos (programas) monetarios concretos, y, en segundo término, porque al aplicarse a una situación de partida caracterizada por la desigualdad entre mujeres y hombres, sin duda el resultado final puede afectar de forma distinta a unas y otros.

Es evidente que el presupuesto influye directamente en la corrección de las desigualdades y en el reforzamiento de la igualdad efectiva intergéneros cuando

\footnotetext{
${ }_{53}$ Al respecto, véase Jubeto, Y. y Dema, S. Larrañaga, M. "Derechos económicos de las mujeres", Reivindicaciones feministas para una ciudadanía transformadora, ACSuR, Universidad del País Vasco, Hegoa, 2011.

${ }^{54}$ Véase Marin BRACHO, E. "Instrumentos de mainstreaming: presupuestos con perspectiva de género", xVI Taller de Politica Feminista: Participación de las mujeres en las politicas de Igualdad hoy, Ed. Forum de Políticas Feministas, Madrid, 2006, pp. 65-76.
} 
refleja decisiones de gasto conectadas con políticas públicas de fomento de la igualdad y de prevención de la discriminación.

Siendo consciente de la especial relevancia del enfoque de género en los presupuestos, y probablemente, sabedora de las debilidades del procedimiento reglamentario arbitrado para la elaboración de los IElG, la Orden EHA/1320/2010, del 18 de mayo, por la que se dictan las normas para la elaboración de los Presupuestos Generales del Estado de 2011, ${ }^{55}$ exonera de aplicación lo dispuesto en la Guía Metodológica de 2009. Así, reza que:

La Memoria no se exigirá con ocasión de la elaboración del anteproyecto de ley de Presupuestos Generales del Estado. El artículo 37.2 de la Ley 47/2003, de 26 de diciembre, General Presupuestaria señala la documentación complementaria que acompañará al proyecto de Ley de Presupuestos Generales del Estado, todo ello sin perjuicio de lo dispuesto en la disposición adicional segunda del Real Decreto 1083/2009, de 3 de julio.

En este sentido, la evaluación del impacto de género que debe recogerse en el IEIG, que acompañe al Anteproyecto de Presupuesto de que se trate, es de tal relevancia que debería partir -en la línea defendida por la Resolución del Parlamento Europeo 2198/2002- de un riguroso diagnóstico de partida, donde se constatara la distribución desigual de bienes, servicios, empleo y representación de mujeres y hombres. Pero, igualmente, debería tener en cuenta las particulares y especificas necesidades e intereses de mujeres y hombres -que pueden o no coincidir-pero que son necesidades e intereses legítimos y específicos a su sexo y humanidad, arbitrando fórmulas de participación de la sociedad civil en la configuración del presupuesto. Dar voz a las mujeres a través de las asociaciones, organizaciones no gubernamentales[...], significa dar volumen a las necesidades silenciadas de éstas como ciudadanas. La consecuencia inmediata descansa en la exigencia de formación en género de las personas expertas que concurran en el diseño del Presupuesto y, en su consecuente grado de sensibilidad, concienciación e implicación con el compromiso de la igualdad efectiva de la ciudadanía, habida cuenta de que deben introducir criterios técnicos complejos, no improvisables ni intuibles.

\footnotetext{
${ }^{55}$ En España, es desde 2009 que se acompaña a los presupuestos, el preceptivo informe de impacto por razón de género, probablemente presionado por el recurso (No. 278/2008) interpuesto por determinadas asociaciones feministas a los presupuestos del año anterior ante la Audiencia Nacional, por omisión grave del referido informe y que será abordado con posterioridad en este ensayo. El informe de impacto de género que acompaña a la Ley de Presupuestos de 2011 identifica 110 programas, agrupados por secciones ministeriales, a los que se les ha realizado el análisis de impacto de género. Al respecto de este recurso y del fallo de la Audiencia Nacional en la sentencia SAN 1702/2010, del 20 de mayo de 2010, véase GIL RuIz, J. M. Las nuevas técnicas legislativas en España, Tirant Lo Blanch, 2011.
} 
JUANA MARÍA GIL RUIZ

De este modo, el Gender Mainstreaming aplicado al Presupuesto exige, en primer lugar, que la perspectiva de género presida todas las fases presupuestarias, no sólo la elaboración sino la previa programación y las posteriores de aprobación y ejecución. En segundo término demanda que se incorpore no como anexo, sino integrado en la agenda política global del Presupuesto. Para terminar con la necesidad de revisión y reelaboración de las prioridades del Estado, que implicará la redefinición de los gastos y la consecuente redistribución de los recursos públicos. No se trata de gastar más, sino de gastar mejor y justamente. "En definitiva, evaluar los presupuestos públicos con perspectiva de género es profundizar en un modelo basado en la eficacia y la eficiencia que permite utilizar más y mejor los recursos disponibles". ${ }^{56}$

En este sentido, la Orden EHA/1320/2010, del 18 de mayo, determina en su artículo 4 las Comisiones participantes en el proceso de elaboración de los Presupuestos Generales del Estado. En el punto 2 de este artículo 4 se concretan las funciones de las Comisiones de Análisis de Programas, que deberán, entre otras, realizar "d) El análisis del impacto de los programas de gasto en igualdad de género". Pero, asimismo, la Orden dedica un punto específico, el 9 del artículo 7 sobre Documentación y plazos para la elaboración de los Presupuestos Generales, a desarrollar el Informe de Impacto de Género, y parece dotar de un cierto papel protagonista a los Organismos de lgualdad, que deberán remitir un informe de observaciones en un plazo de 15 días, así como un cierto papel representativo en el equipo final que redactará el Informe de Impacto de Género que acompañará al anteproyecto de Ley de Presupuestos Generales del Estado.

Merece la pena la transcripción del precepto:

7.9. Informe de impacto de género. Los departamentos ministeriales remitirán a la Secretaría General de Presupuestos y Gastos un informe analizando el impacto de género de sus programas de gasto, en los términos que se establezcan al efecto por la citada Secretaría General.

La Asesoría Jurídica de dicha Secretaría General solicitará informe a la Dirección General de Presupuestos del Ministerio de Economía y Hacienda y a la Secretaría General Técnica del Ministerio de lgualdad, que habrán de remitir las observaciones que en su caso procedan en el plazo máximo de 15 días. Si transcurrido este plazo dichos Centros Directivos no han formulado observaciones se considerará adecuada la documentación original remitida por los Ministerios.

Dichos informes constituirán la base para la formulación por parte de la Secretaria General de Presupuestos y Gastos del Informe de Impacto de Género, a cuyos efectos

${ }^{56}$ Informe de impacto de género que acompaña a los presupuestos en tramitación parlamentaria relativos al ejercicio de 2011. Consultable en internet en www. pap.meh.es/sitios/sgpg/es.Es. 
se constituirá un grupo de trabajo integrado por representantes del Ministerio de lgualdad, de la Secretaría General de Presupuestos y Gastos y de la Dirección General de Presupuestos para conformar la redacción final del lnforme del lmpacto de Género que acompañará al anteproyecto de Ley de Presupuestos Generales del Estado.

Esta participación o intervención de Ministerio de lgualdad (actual Ministerio de Sanidad, Política social e lgualdad), en la constitución de la Comisión última o grupo de trabajo que reelaborará el IEIG en su redacción final, garantiza, en cierto modo, la experticia en género que deben tener las personas que concurran en el diseño de los presupuestos, y, sobre todo, la fiscalización interna de que el Anteproyecto de Ley de Presupuestos Generales del Estado está diseñado en clave de género, partiendo de un diagnóstico de partida, a través de indicadores concretos y coherentes, y dirigidos a los objetivos de las políticas de igualdad identificados en la legislación específica.

La diferente previsión de procedimiento y los distintos criterios exigidos en la elaboración de los IEIG, con carácter general, y el específico para los Presupuestos Generales del Estado, nos plantea la duda de si el compromiso con la transversalidad de género es real y coherente, o simplemente un mero trámite que debe cumplirse ante Europa.

\section{Conclusiones y propuestas}

Actualmente, y en teoría, ya no hay excusas, pues la reglamentación específica del IEIG, recordada por la disposición adicional 10a. de la L.0. 3/2007, del 22 de marzo para la lgualdad Efectiva de Mujeres y Hombres, es hoy una realidad. Sin embargo, y pese a su reciente regulación del 11 de diciembre de 2009, resulta fundamental reparar en los siguientes extremos, y subsanar, en un futuro -confiemos próximo-, las disfunciones de ese vacío legal tan nocivo que, incluso aún hoy, tras su desarrollo reglamentario -a todas luces deficitario y difuso, pues apenas asciende a cuatro páginas la referencia al impacto por razón de género-, quedan sin cubrir, y que sin duda siguen colocando al IEIG en una posición de mero formulario más, que debe ser cumplimentado para continuar con el procedimiento legislativo. A modo de sumario, se ha de reparar en:

1) Determinación del organismo, de carácter paritario, que debe ser el responsable de los IEIG, no limitándose a señalar quién debe emitirlos, sino que determinará los criterios para tal objetivo, tanto en el proceso de ela- 
JUANA MARÍA GIL RUIZ

boración, redacción y validación. Asimismo, los IEIG deben estar firmados, fechados y sellados, y su autoría debe quedar claramente prefijada, con evidente participación femenina (que no sólo masculina, como es la tónica actual). En este sentido, resulta requisito sine qua non que las personas responsables de emitir los IEIG tengan formación en género. Entendemos que los Organismos de lgualdad deben tener presencia como uno más de los interlocutores válidos en la tarea de elaborar y redactar el IEIG, pero no debe ser una responsabilidad exclusiva de éstos, sino que ha de ser una participación colegiada y coordinada con el órgano o centro directivo impulsor y responsable de la propuesta normativa, quien deberá -en nuestra opinión- nombrar una comisión encargada de su presentación motivada en tiempo y forma, garantizando en todo momento su experticia en la metodología de género.

2) Entendemos, igualmente, importante que se extrapolara el sistema andaluz que exige, amén de un IEIG, un IOIEg que lo completara (Informe de Observaciones del Informe de Evaluación del Impacto de Género), que debe ser elaborado por el Organismo de lgualdad competente; a saber, el Instituto de la Mujer, que, en cierto modo, garantizara su nivel de competencia y que en todo caso debiera ser vinculante. Algunos de los datos que debe recoger este Informe de Observaciones del lnforme de Evaluación del Impacto de Género son:

a) Que el IEIG revisado se haya formulado siguiendo las directrices de la recién aprobada Guía Metodológica para la elaboración de la Memoria del Análisis de Impacto Normativo, del 11 de diciembre de 2009.

b) Que la descripción de la situación de partida, diagnóstico necesario para el éxito del informe, haya recogido los datos estadísticos desagregados por sexo, especialmente los elaborados por el Instituto de Estadística.

c) Supervisión del lenguaje sexista, colaborando en la implantación de un lenguaje no sexista en el ámbito administrativo, tal y como se recoge en el artículo14 de la L.o. 3/2007, del 22 de marzo, para la lgualdad Efectiva de Mujeres y Hombres. Se evitará el uso de formas discriminatorias o androcéntricas, o la utilización del masculino genérico, de forma que la terminología empleada esté en armonía con el principio de igualdad de sexos. ${ }^{57}$

\footnotetext{
57 En este sentido, véase Vigara Tauste, A. y Jiménez CatalÁn, R. Género, sexo, discurso, Ed. Laberinto, Madrid, 2002. Asimismo, remito a Medina GuerRa, A. M. (coord.). en Manual de lenguaje administrativo no sexista, Asociación de Estudios Históricos sobre la Mujer de la Universidad de Málaga, Ayuntamiento de Málaga, 2002.
} 
d) Composición paritaria del órgano o centro directivo impulsor y responsable de la propuesta normativa.

e) Si la disposición normativa o reglamentaria pretende crear un órgano o comité, éste deberá ser también paritario.

f) La propuesta normativa o reglamentaria de que se trate debe afectar por igual a mujeres y a hombres.

g) Recomendación de modificación de todos aquellos aspectos que hayan obtenido una evaluación de impacto negativo; es decir, cuando no se prevea una eliminación o disminución de las desigualdades detectadas, sino, todo lo contrario, que no contribuya a las políticas de igualdad.

3) Concreción del momento y desarrollo exactos de estos IEIG, así como de los IOlEG, e imposición de su carácter vinculante. Deben ser, en todo caso, anteriores y paralelos a la presentación de la iniciativa parlamentaria que se pretende aprobar, y en todo caso, deberán ser positivos. Se valorará el impacto de género de la disposición como positiva, cuando se prevea una disminución o eliminación de las desigualdades detectadas y contribuya a los objetivos de las políticas de igualdad.

4) Establecimiento de pautas homogéneas que permitan elaborar informes en tres ámbitos: en el ámbito interno (en un mismo Ministerio/Consejerías); en el ámbito externo (pautas comunes en los IElg elaborados en los distintos Ministerios/Consejerías), y en el territorio nacional (homogeneidad en el fondo y en la forma entre los distintos IEIG que se elaboren en el Estado español).

5) Diseño y establecimiento de seguimiento y posterior evaluación de todos los IEIG, así como de los IOIEG, que deberán llevarse junto al texto definitivo que pretende aprobarse y que, en todo caso, deberían tener carácter preceptivo y vinculante. Algunas Comunidades Autónomas, como la andaluza, lo prevén, sin embargo, pese a dotar de un cierto peso específico al Instituto Andaluz de la Mujer, lamentablemente su informe de observaciones sigue sin poseer carácter vinculante en la actualidad.

6) Previsión de mecanismos que posibiliten la evaluación de los niveles de eficacia y eficiencia reales de los IElG -y de los IOIEG, si se exigieran-, y su impacto en la formulación y ejecución y aplicación de las disposiciones normativas. Este apartado debería tener conexión con la exigencia europea que obliga a adoptar "las medidas necesarias para garantizar que [...] se derogue cualquier disposición legal, reglamentaria o administrativa contraria 
JUANA MARÍA GIL RUIZ

al principio de igualdad de trato". ${ }^{58}$ Esta función garantista, no prevista en el Real Decreto 1083/2009, del 3 de julio, ni en consecuencia en la Guía Metodológica para la elaboración de la Memoria del Análisis de impacto normativo, debiera descansar en la atribución de competencias a los organismos de igualdad, quienes, tras evaluar los niveles de eficacia y eficiencia reales de los IEIG en primer término, y de la disposición normativa a posteriori, debieran ostentar la potestad de emitir un informe vinculante de derogación automática de la normativa discriminatoria. En este sentido, la actuación derogatoria del órgano normativo -el mismo emisor de la norma discriminatoria u otro órgano con poder normativo superior- deberá estar garantizada, no bastando con la obligación de integrar la dimensión de género en la elaboración normativa, debiendo haber una adicional garantía de integración. ${ }^{59}$

7) Controles judiciales de constitucionalidad de las leyes o de legalidad de los reglamentos, como medida de supresión de la norma discriminatoria en caso de haber sido valorada como tal; así como exigencia previa motivada de los IEIG como garantía del efectivo cumplimiento del principio de transversalidad, requisito sine qua non del ejercicio válido de la potestad reglamentaria, con transcendencia invalidante.

De cualquier modo, un compromiso real con la igualdad efectiva por parte de los responsables políticos y equipos técnicos, que descansara en una óptima formación en género, hubiera apoyado e impulsaría - sin excusas reglamentistas- la implementación de los IEIG en todas sus fases, en la Guía de la Comisión Europea de 1998 para la Evaluación del Impacto en Función de Género, o incluso se hubiera acogido, de modo coherente, con las pautas determinadas en la Guía encargada por el Instituto de la Mujer, de $2005,{ }^{60}$ pero no fue así.

Según lo dicho, urge un correcto y comprometido (con el Gender Mainstreaming) desarrollo reglamentario del despliegue del impacto de género, pero también la apuesta por la persecución motivada de los IEIG por el Legislativo, el Ejecutivo, y cómo no, su fiscalización por parte de los tribunales de justicia. ${ }^{61}$

\footnotetext{
${ }_{58}$ Recordemos que se trata de la nueva redacción del artículo 3.2.a) de la Directiva 2002/73/CE, que modifica la Directiva 76/207/CEE, ya referida en nuestro estudio con anterioridad.

${ }^{59}$ Cfr. Lousada ArochenA, J. F. "El informe sobre el impacto de género en la elaboración normativa", en La Ley, No. 6092, septiembre de 2004, pp. 1-4.

${ }^{60}$ Guía de aplicación práctica para la elaboración de Informes de Impacto de Género de las Disposiciones Normativas que elabore el Gobierno, de acuerdo a la Ley 30/2003, elaborada por Fundación Mujeres, Instituto de la Mujer, 2005.

${ }_{61}$ Al respecto, véase Las nuevas técnicas legislativas en España, Tirant lo Blanch, 2011.
} 
En este sentido, reparar y formar a profesionales del derecho, de la política y de la administración en la complejidad del Gender Mainstreaming resulta de vital importancia para la correcta implementación de los IEIG, si realmente se reputa a los mismos, tal y como reza la Exposición de Motivos de la Ley de lgualdad, instrumentos básicos y esenciales de la política de igualdad intergéneros. 